\title{
Case Study and Assessment on Vessel Structure Safety
}

\author{
Xiaobin Yang \\ School of Economics \& Management, Shanghai Maritime University, Shanghai, China \\ Email: btxiaoding@126.com
}

How to cite this paper: Yang, X. B. (2020) Case Study and Assessment on Vessel Structure Safety. World Journal of Engineering and Technology, 8, 756-764. https://doi.org/10.4236/wjet.2020.84054

Received: August 16, 2020

Accepted: November 17, 2020

Published: November 20, 2020

Copyright $\odot 2020$ by author(s) and Scientific Research Publishing Inc. This work is licensed under the Creative Commons Attribution International License (CC BY 4.0).

http://creativecommons.org/licenses/by/4.0/

\begin{abstract}
From the case study, the nature defects of single-hull vessel were discussed to compare the safety level between single-hull vessel and double-hull vessel. Data was chosen from both investigation and research from ABS, as well as simulation by similar kind of vessel in model calculation. The study underscores the main defects of single-hull vessel for prevention of their losses, mentioning the most important measures taken by IMO for improvement of vessel safety. In the work, a critical analysis of the methodology of the International Association of Classification Societies (IACS) for calculation of sectional efforts induced by waves in vessel's hull is described. In the end, the advantage of double-hull vessel was determined and the reason to eliminate single-hull vessel was proved again.
\end{abstract}

\section{Keywords}

ABS Standards, Strength Assessment, Delphi Method, Vessel Construction Safety

\section{Introduction}

On November 13, 2002, the PRESTIGE was reported flooding preceded by a sudden vibration or severe shudder. With such significant list, the PRESTIGE lost propulsion and began to drift. After Spanish authorities refused to allow the PRESTIGE safe harbor, on the morning of November 19, 133 nautical miles off the coast of Spain in international waters, the PRESTIGE broke in two and sank.

The ecological result of the PRESTIGE casualty was a massive 70,000-ton oil spill that devastated the local fishing and tourism industries. Due to the toxic nature of the oil, it was predicted to cause pollution in the area for ten years after the initial spill, coating over one hundred miles of Spanish and French coastline with toxic oil. The spill had an estimated clean-up cost of nearly three billion US 
dollars.

As an ABS class vessel, ABS was sued by EU for the loss caused by PRESTIGE, claiming that they were responsible for the damage, because the flaw in the hull structure should have been caught by an ABS inspection. ABS made extensive technical analyses of the PRESTIGE after the incident, but the lack of physical evidence prohibited them from reaching a definite conclusion. The vessel was properly loaded and the as-built hull structure met the 1973 ABS Rule requirements as well as the 2003 ABS Rule and IACS Unified Rule. Some as-built structural details failed the 2003 ABS requirements for fatigue, but ABS maintains that this is not a probable cause of the hull failure, as the PRESTIGE operated in a gentler environment than the criteria were developed for, and "most of the side longitudinal having insufficient fatigue life was renewed at the 4th and 5th Special Hull Surveys". In its intact state, the PRESTIGE was under the allowed values for still-water bending moment and shear force. According to their technical analyses, ABS believes that "a weakened section in the side hull or supporting framing in the vicinity of frame 71" caused the initial damage and flooding. ABS considered lightering damage to be the most likely cause of the side hull weakening. According to the ABS analysis, with these lightering operations, "permanent deformations of side longitudinal Nos. 32 to 34 and the transverse frames and transverse bulkhead could have occurred in the vicinity of frame 71 ". In fact, a sister vessel of the PRESTIGE sustained side hull damage from lightering in 1989 [1].

In order to avoid such kind of tragedies again, in 2003, EU has introduced laws to restrict single-hull oil tankers operating in waters. This paper aims to analyze the nature defects of single-hull vessel and try to find an explanation on the reasons to hull breaking down.

\section{Comparison between Single-Hull Tankers and Double-Hull Tankers on Oil Spill Risk}

Compared with single-hull tankers, double-hull tankers have a lower oil spill risk. The two stranding accidents in Milford Haven, Wales, showed that even if the double hull vessel suffered stranding damage to the outer hull, if the internal medicine is intact, no oil leakage will occur, while the single layer hull vessel will be damaged if it is rubbed. It will cause a lot of oil leakage and pollution. According to statistics, the main causes of oil tanker accidents are hull and mechanical defects, collisions hit the rocks and run aground. The most likely areas for reef strike and stranding accidents are near-shore waters and waterways. In these areas, vessels generally travel at lower speeds. It is foreseeable that collisions in these areas are of low intensity. According to many accidents and research, double-hulled hulls can withstand low-intensity collision damage more than single-hulled hulls, and are therefore less prone to oil leakage pollution than single-hulled hulls.

In order to further explain the difference in vessel strength between the double-layer hull and the single-layer hull, the following will analyze the total 
longitudinal strength of the single-layer hull to explain the defects of the single-layer hull in the total longitudinal strength, and why the double-layer hull or The special double-deck reinforced design can make up for this defect.

The break-up of the hull can be attributed to the continuous wave impact and internal sloshing the vessel incurred as it was towed out to sea. According to the calculations made by ABS, after the vessel was counter-flooded, the still-water bending moment was 154 percent of the allowable value and the shear force was 93 percent of the allowable value.

Here is the detailed vessel description of MV. PRESTIGE:

Vessel Particulars

LOA: $243.5 \mathrm{~m}$

Breadth: $34.4 \mathrm{~m}$

Depth: $18.7 \mathrm{~m}$

Draft: $14.0 \mathrm{~m}$

Gross Tonnage: 42,820

Deadweight: 81,589 tons

Design Speed: 15.4 Knots

Builder: Hitachi Vessel Building and Engineering Co. (Maizuru Works), Japan

Hull No.: 4437

Year Built: 1976

ABS ID No.: 7,603,948

IMO No.: 7,372,141

Flag: Bahamas

Port of Registry: Nassau

Registered Owner: Mare Vessel ping, Inc., a Liberia corporation

Manager: Universe Maritime Ltd, Greece

P\&I Coverage: The London Steam Vessel Owner's Mutual Insurance Association

Vessel Type: Single-hull tanker; Category 1 vessel under MARPOL 13G requirements; at time of incident, approved as CBT product tanker with 30 percent side protection

Hull Material: Mild steel, subject to IACS Enhanced survey program

Coordinated studies showed that losses caused by hull breaking down depended probabilistically on certain factors:

- vessel's age, increasing with that;

- type of cargo, increasing with its specific gravity;

- chosen trade route, the most dangerous being trade routes of Far East and Northern Atlantic;

- type of material used in vessel hull construction, high strength steels increasing the risk to lose the vessel as they are prone to corrosion. They have smaller allowances and ensure a greater elasticity of the hull, fostering the phenomenon of springing (manifestation of vessel general vibration induced by waves which stress her additionally and determine the decreasing of fatigue resistance) and whipping phenomenon. 
The hull structure, even in its counter-flooded condition, was capable of remaining intact, and did so for six days as it was under tow. The additional dynamic wave loads, however, augmented the bending stress, and once the deck plate reached its buckling strength, the structure broke in two. According to the calculation results, under the same lateral load, the maximum stress of single and double hull vessels is $168 \mathrm{Mpa}$ and $172 \mathrm{Mpa}$, respectively, which are lower than the allowable stress of CCS (the allowable stress of transverse bulkhead is $145 \mathrm{Mpa}$, and the remaining allowable stress of construction is $175 \mathrm{Mpa}$ ), the combined stress of each member of the two vessels is at a low level, meeting the strength requirements, and the deformation of the two vessels is small.

The two vessels with 25,000 t class single-hull double-bottom and double-hull double-bottom have the same main dimensions were chose as the samples for the comparison calculation. The vertical line is 151 meters long, 25 meters wide and 13.8 meters deep. Both vessels have three cargo compartments, each of which has a length of 38 meters. The relevant dimensions of the cargo compartment area are rib spacing $700 \mathrm{~mm}$, double bottom height $1400 \mathrm{~mm}$, and strong frame spacing $2100 \mathrm{~mm}$. Both have eight double bottom stringers.

Basically, the main components of the two vessels showed the maximum combined stress in the fully loaded compartment, and it can be found that the two models have the largest deformation on the side panel during the fully loaded compartment. Therefore, the intensity and stability of propagation have the greatest impact and are the most dangerous loading conditions. According to the stress distribution of each member, the parts where the stress concentration easily occurs under the lateral load are the cargo corners, the openings of the ribs and bottom stringers, and the structure of the attachments of the transverse bulkhead. The main cause of stress concentration is the discontinuity of the structure and the uneven distribution of the load. Local reinforcement measures such as thickening plates around the openings and the use of reinforcing ribs can be used to reduce stress. The large-scale high-stress areas appear on the ribs.

Comparing the combined stress and deformation results of the members of the single-hull vessel and the double-hull, it can be found that the overall stress and deformation level of the double-hull vessel is lower than that of the single-hull vessel. From the perspective of deformation, the outboard survey of double-hulled vessels is significantly lower than that of single-hulled vessels. In general, double-hulled vessels have better stability and lateral strength than single-hulled vessels, and their double-side structure can effectively transmit lateral loads.

\section{Strength Assessment of Single-Hall Vessels}

For safe operation of vessels, they must perform the voyage loaded in accordance with loading manual or in accordance with a cargo-plan developed by the crew using loading instrument existing onboard, which was previously approved by the classification society. Loading and unloading of vessel at terminals shall be 
carried out in accordance with Manual on loading/unloading sequences existing onboard or a plan with loading/unloading sequences developed by the crew using loading instrument.

Likewise, the general strength assessment of vessels in operation is conducted when periodical surveys at 5 years interval, of intermediate surveys carried out at 2.5 years interval and of annual surveys [2]. When periodical and intermediate surveys, thickness measurements of stiffeners are carried out, by companies authorized by classification society or competent naval authority, measurements which shall be registered on forms to be kept in a folder onboard.

Measured reduced plating thicknesses are compared with maximum reduced thicknesses accepted, and in case these accepted reduced thicknesses are exceeded, the stiffeners are replaced. Maximum decreases accepted are usually corrosion allowances adopted at design stage [3].

Greater reduced thicknesses could be accepted, but in this case the assessment process of general and local strength of design phase shall be recommenced, with the exception that initial thicknesses of stiffeners are those of the Report of thicknesses' measurements. Based on this assessment, restrictions in vessel operation could be imposed and the Loading Manual, Stability Booklet, the Loading Instrument and Manual of loading/unloading sequences in case of vessel shall be modified accordingly.

At annual survey, the followings shall be visually verified by sampling: the integrity of stiffeners, the presence onboard of Loading Manual and correct functioning of Loading Instrument. Oil tankers and vessel are subject of the enhanced program of inspections in conformity with 2011 ESP Code (IMO Rez. A.1049 (27)) and MSC.287 (87).

The Common Structural Rules for Vessel and Oil Tankers introduce the approach of stiffeners renewal criterion if the corrosion allowance was lost from initial thickness established by design. Fatigue strength assessment is realized through detailed inspection and non-destructive examination of structural joints most exposed at variable loads indicated by designer, in order to track down possible cracks specific to fatigue phenomenon.

If these tests were carried out after $Y$ years since the putting into service of the vessel and in laboratory the residuary cumulative damage factor $D_{r}$, which remained until the break, then the real operational life of the vessel $L_{r}$ can be found using equation:

In case when cracks are discovered due to material fatigue before expected life of the vessel expires, the fatigue strength of structural joints affected by this phenomenon will be reassessed, these joints will be redrawn and the cracked and tired stiffeners will be replaced by new redrawn stiffeners, and the inspection of joints will be carried annually. Moreover, during the inspections, anticorrosive protection is verified and if it is found damaged, it will be reconditioned.

\section{Discussions by Delphi Method}

As discussed in last chapter, for environmental protection considerations, sin- 
gle-hull vessels are no longer suitable for international oil transportation services, especially under the premise that major economies in the world have banned the use of single-hull hulls. The disposal of these single-hull vessels has become a new issue. In order to discuss the handling of single-hull vessels from a more objective point of view, the author considered the Delphi method to deal with this problem. This issue was discussed by selecting anonymous professionals from the shipping industry to issue questionnaires. For the sake of objectiveness and fairness, although the selected expert information is hidden in this article, the basic data of the experts are summarized as shown in Table 1.

The questionnaire was designed in two batches. In the first batch, there were two main questions.

Question 1: From 1 - 10, whether to support the elimination of single-hull vessels to transport oil, 1 is strongly against and 10 is strongly agree.

Question 2: From 1 - 10, whether to support the dismantling of all single hull vessels, 1 is strongly against and 10 is strongly agree.

After the retrieving of all questionnaires, the second questionnaire was designed containing two questions below:

Question 3: From 1 - 10, whether to support the modification of single-hull vessel to meet other maritime requirements, 1 is strongly against and 10 is strongly agree.

Question 4: Potential options for single-hull vessel modification.

Table 2 indicates the retrieving results for the questionnaires and Table 3 shows the scoring result for the two batch questionnaires.

According to the above results, all the questionnaires are effective so we can get the effective results in Table 3 as below.

Table 1. Expert information.

\begin{tabular}{ccc}
\hline Project Expert Information & quantity & ratio \\
\hline Age & 2 & $13.33 \%$ \\
$30+$ & 6 & $46.15 \%$ \\
$40+$ & 7 & $46.67 \%$ \\
$50+$ & & \\
Work Experience & 3 & $20.00 \%$ \\
$10+$ & 5 & $33.33 \%$ \\
$20+$ & 7 & $46.67 \%$ \\
$30+$ & & \\
Education background & 4 & $26.67 \%$ \\
bachelor & 5 & $33.33 \%$ \\
master & 6 & $40.00 \%$ \\
doctor & & \\
\hline
\end{tabular}


Table 2. Retrieving of the questionnaires.

\begin{tabular}{cccccc}
\hline Questionnaire & release & retrieve & retrieve ratio & effective & effective ratio \\
\hline first batch & 15 & 15 & $100 \%$ & 15 & $100 \%$ \\
second batch & 15 & 15 & $100 \%$ & 15 & $100 \%$ \\
\hline
\end{tabular}

Table 3. Scoring results of the questionnaire.

\begin{tabular}{lcccc}
\hline Scoring Result & Q1 & Q2 & Q3 & Q4 \\
\hline Expert 1 & 9 & 7 & 8 & double-hull tanker \\
Expert 2 & 9 & 8 & 8 & bulk \\
Expert 3 & 8 & 4 & 9 & bulk \\
Expert 4 & 9 & 8 & 8 & bulk/double-hull tanker \\
Expert 5 & 8 & 5 & 9 & offshore engineering \\
Expert 6 & 10 & 8 & 7 & double-hull tanker \\
Expert 7 & 9 & 7 & 9 & bulk/double-hull tanker \\
Expert 8 & 9 & 6 & 9 & offshore engineering \\
Expert 9 & 8 & 5 & 10 & double-hull tanker \\
Expert 10 & 10 & 9 & 9 & bulk \\
Expert 11 & 9 & 7 & 8 & offshore engineering \\
Expert 12 & 9 & 8 & 9 & bulk \\
Expert 13 & 10 & 10 & 8 & bulk/double-hull tanker \\
Expert 14 & 9 & 5 & 10 & double-hull tanker \\
Expert 15 & 9 & 6.87 & 967 offshore engineering \\
Average & 9 & & & \\
\hline
\end{tabular}

According to the results of this scoring result in Table 3, although most experts agree with the elimination of single-hull transportation, they do not agree with direct dismantling, because it is considered that the act of dismantling vessels may also pollute the environment. Therefore, according to the opinions of most experts, instead of direct elimination, it is more appropriate to adopt ship modification to adapt to other forms of transportation for smaller vessels. The main choices are direct modification to double hull vessels and bulk vessel or offshore engineering.

\section{Conclusions and Proposals}

In the paper, the problems on the single-hull vessels safety have been treated. The requirements for estimating the vessel hull general strength have been presented. The methods are illustrated by two examples of the sectional efforts' estimation. According to the results, certain inconveniencies after the great accidents occurring in the last decades have been expressed by the vessel builders 
and operators. The data showed that from 1126 of fatalities, $69.70 \%$ were due to side hull failures (785). Also, it was found that from 1982 to 2001, the side hull failures led to the sinking of 72 classic vessels and a single with the double bottom [4]. Furthermore, the vessels were broken through deck collapse which meant that they were under scantling for sagging bending moment and consequently revising the formula for its calculation was required [5]. Problems come into attention of IMO, which are concluded in.

Furthermore, this organization imposed since 1st July 2006 through Regulation XII/6.2 of SOLAS Convention, that vessel over $150 \mathrm{~m}$ in length to have double side [6]. Taking into consideration those presented hereinbefore, in order to improve vessel construction safety, according to the new proposal, in the case of the general cargo vessel, for additional maximum bending moments, differences are less than $6 \%$ and for additional maximum shear forces, differences are less than $5 \%$. In the case of the bulk carrier, for additional maximum bending moments, differences are less than $1 \%$ and for additional maximum shear forces, differences are less than $4 \%$. These differences could be considered as acceptable. It is worth noting that formulae are revised only relating to sectional efforts determined for vessel quasi-static layout on wave. It is necessary that such analysis should be carried out for dynamic layout on wave as well and if bigger efforts are obtained, this means revising again the afore-mentioned formulae. From the assessment carried out, it shows that IACS formulae for calculation of additional sectional efforts induced by waves must be corrected, because these efforts are exceeded in real situations in which vessel layout is quasi-static on wave, as in cases where vessel navigates with wave from astern. If uncorrected IACS formulae continue to be used, imposes as a first measure to improve vessel construction safety since design phase, the determination of sectional efforts at quasi-static layout on wave through direct calculations and if those have greater values as those obtained with IACS formulae, the scantling of longitudinal structure of vessel will be carried out taking into account of respective values.

According to the expert opinions obtained by the Delphi method, compared with the direct dismantling of vessels, the transformation of single-hull vessels facing elimination for other purposes is more in line with the original intention of environmental protection, and also more in line with the shipping industry, especially the oil tanker companies' economic benefit.

In addition, whether it is an oil trading operation or a crude oil storage operation, using oil tankers as offshore floating warehouses is a good solution. It is reported that in March 2009, the United States used 30 supertankers for offshore oil storage, with oil storage of more than 80 million barrels [7], close to the global single daily oil production. It can be seen that under the impact of the financial crisis, the shipping industry is in a downturn, and the oil demand of various countries has declined. The implementation of oil reserves is becoming a strategic choice for all countries. Against this background, oil tankers are facing huge business opportunities. 


\section{Conflicts of Interest}

The author declares no conflicts of interest regarding the publication of this paper.

\section{References}

[1] Shi., J. (2016)Discussion on the Future Development of Single-Hull oil Tankers under $600 \mathrm{dwt}$ in our Inland River. Zhujiang Shuiyun, No. 5, 94-96.

[2] Li, N. (2016) Design and Study on Tubular Side Structure Impact Resistance and Mechanical Properties. Jiangsu University of Science and Technology, No. 3, 34-36.

[3] Yu, R., Liu, J.-X., Huang, Z.-Q. and Ye, W.-B. (2012) Analysis on Energy Absorption of Ship Side Structures in Collision Based on Simplified Analysis Method. Ship Engineering, No. 4, 41-44.

[4] Andreas, I. (2010) Ultimate Longitudinal Strength of Corroded and Damaged Bulk. Doctorate Thesis, Dunărea de Jos University of Galați, Galați.

[5] Lupascu, D. and Chirica, I. (2015) Assessment of Seagoing Ships Longitudinal Strength in the Context of International Rules, Important Factor for Safe Operation. World Journal of Engineering \& Technology, 3, 291-310. https://doi.org/10.4236/wjet.2015.34029

[6] IMO (1974) International Convention for the Safety of Life at Sea (SOLAS).

[7] An, F. (2010) The Road for Rebirth of Single-Hull Oil Tankers. China Ship Survey, No. 1, 46-48, 127. 